\title{
POLÍTICAS EDUCACIONAIS SOB A PERSPECTIVA DA DIFERENÇA: A POTÊNCIA QUEER DAS ESCOLAS NO CONTEXTO DA PRÁTICA
}

\author{
Jeinni Kelly Pereira Puziol ${ }^{1}$, Ana Cristina Teodoro da Silva ${ }^{2}$ \\ ${ }^{1}$ Pós-Doutora pela Escola de Comunicação da Universidade Federal do Rio de Janeiro - ECO/UFRJ. Doutora em \\ Educação pela Universidade de São Paulo - USP. Professora adjunta temporária do Departamento de Teoria e Prática \\ da Educação da Universidade Estadual de Maringá - UEM, PR. ORCID iD: https://orcid.org/0000-0003-1897-6821 E- \\ mail: jkppuziol2@uem.br \\ ${ }^{2}$ Pós-Doutora pela Escola de Comunicação da Universidade Federal do Rio de Janeiro - ECO/UFRJ. Doutora em História \\ pela Universidade Júlio de Mesquita Filho - UNESP. Professora associada do Departamento de Fundamentos da \\ Educação, no curso de Comunicação e Multimeios da Universidade Estadual de Maringá - UEM, ORCID iD: \\ https://orcid.org/0000-0002-5105-4936 E-mail: actsilva@uem.br
}

\section{RESUMO}

A proposta deste ensaio teórico é discutir a potência queer no contexto da prática das escolas a partir das políticas educacionais realizadas sob a perspectiva da diferença e não da diversidade. Pensar as políticas educacionais sob a concepção da diferença possibilita transformações na relação com outro e consigo mesmo, de modo a enfrentar os conflitos sociais, econômicos, culturais e históricos, sustentados nos privilégios de gênero, cor, etnia, orientação sexual e classe. A perspectiva da diversidade é pautada na ideia de tolerância e do contorno aos conflitos históricos, colorindo a realidade sem questionar a causa das desigualdades. No contexto da prática das escolas, mesmo diante do discurso hegemônico da diversidade, é possível realizar as políticas educacionais sob a perspectiva da diferença, como por exemplo, a obrigatoriedade do ensino de História e Cultura Afro-Brasileira (2003) no ensino fundamental e médio e o Programa Brasil Sem Homofobia (2004), pois mesmo sendo um lugar fundamental da normatização da vida, a escola é também espaço potente, faz parte das margens que levam a repensar a educação incorporando grupos e experiências historicamente subalternizadas, com isso desfazendo fronteiras. $\mathrm{O}$ artigo faz dialogar a filosofia da diferença de Deleuze (1996) com a perspectiva queer das discussões sobre gênero e sexualidade de Butler (2015), Scott (2005) e Miskolci (2012), procurando constituir territórios teóricos subversivos.

Palavras-chave: Margem; Fronteira; Potência de vida;

\section{EDUCATIONAL POLICIES FROM THE DIFFERENCE PERSPECTIVE: THE QUEER POWER OF SCHOOLS IN THE CONTEXT OF PRACTICE}

\begin{abstract}
The purpose of this theoretical essay is to discuss queer power in the context of school practice based on educational policies carried out from the perspective of difference and not diversity. Thinking about educational policies under the conception of difference enables transformations in the relationship with others and with oneself, in order to face social, economic, cultural and historical conflicts, based on the privileges of gender, color, ethnicity, sexual orientation and class. The perspective of diversity is based on the idea of tolerance and the contour of historical conflicts, coloring reality without questioning the cause of inequalities. In the context of school practice, even in the face of hegemonic diversity discourse, it is possible to carry out educational policies from the perspective of difference, such as, for example, the obligation to teach Afro-Brazilian History and Culture (2003) in elementary and high school and the Brasil Sem Homofobia Program (2004), because even though it is a fundamental place in the standardization of life, the school is also a powerful space, it is part of the margins that lead to rethinking education, incorporating historically subordinated groups and experiences, thereby breaking down borders. The article dialogues Deleuze's (1996) philosophy of difference with the queer perspective of the discussions on
\end{abstract}


gender and sexuality by Butler (2015), Scott (2005) and Miskolci (2012), seeking to constitute subversive theoretical territories.

Keywords: Margin; Border; Life power;

\section{POLÍTICAS EDUCATIVAS DESDE LA DIFERENCIA PERSPECTIVA: EL PODER QUEER DE LAS ESCUELAS EN EL CONTEXTO DE LA PRÁCTICA}

\section{RESUMEN}

El propósito de este ensayo teórico es discutir el poder queer en el contexto de la práctica escolar a partir de políticas educativas realizadas desde la perspectiva de la diferencia y no de la diversidad. Pensar en políticas educativas bajo la concepción de la diferencia posibilita transformaciones en la relación con los demás y con uno mismo, para enfrentar conflictos sociales, económicos, culturales e históricos, basados en los privilegios de género, color, etnia, orientación sexual y clase. La perspectiva de la diversidad se basa en la idea de tolerancia y el contorno de los conflictos históricos, coloreando la realidad sin cuestionar la causa de las desigualdades. En el contexto de la práctica escolar, incluso frente al discurso de la diversidad hegemónica, es posible realizar políticas educativas desde la perspectiva de la diferencia, como, por ejemplo, la obligación de enseñar Historia y Cultura Afrobrasileña (2003) en la escuela primaria y secundaria. y el Programa Brasil Sem Homofobia (2004), porque si bien es un lugar fundamental en la estandarización de la vida, la escuela también es un espacio poderoso, es parte de los márgenes que llevan a repensar la educación, incorporando grupos y experiencias históricamente subordinados, deshaciendo fronteras. El artículo dialoga la filosofía de la diferencia de Deleuze (1996) con la perspectiva queer de las discusiones sobre género y sexualidad de Butler (2015), Scott (2005) y Miskolci (2012), buscando constituir territorios teóricos subversivos.

Keywords: Margen; Frontera; Poder vital;

\section{BRASIL DE HOJE E DE ONTEM: A EDUCAÇÃO COMO NORMATIZAÇÃO E POTÊNCIA DE VIDA}

O presente distópico que atemoriza o Brasil é realçado pela política realizada pelo governo federal, mas também pelas políticas do passado, pois este governo é consequência da polarização acirrada no país com a desvalorização da democracia e de suas instituições. Num passado não muito distante, como em $1930 \mathrm{com}$ o impedimento da posse de Júlio Prestes e a assunção autoritária de Getúlio Vargas, ou em 1964 com o golpe militar e a deposição do então presidente João Goulart, o respeito pela democracia em constituição oscilava em nome da suposta defesa da segurança nacional, disfarçando os interesses econômicos e de poder que sustentavam $o$ ato autoritário.

A narrativa política do governo federal inventa e distorce dados e informações, como sintetizado no discurso ${ }^{1}$ de abertura da Assembleia Geral da Organização das Nações Unidas (ONU) em 22 de setembro 2020. Tal narrativa é uma expressão de nosso presente e

\footnotetext{
10 discurso pode ser lido em: https://noticias.uol.com.br/politica/ultimas-

noticias/2020/09/22/leia-a-integra-do-discurso-de-bolsonaro-naassembleia-geral-da-onu.htm
}

nossa história, nacional e global. É preciso que questionemos como e porque uma parte da população concorda, aplaude e até mesmo se diverte com o discurso de ódio contra minorias, a valorização judaico-cristã em detrimento de outras religiões, a atribuição das queimadas na Amazônia e Pantanal aos índios e caboclos, a negação dos problemas de gênero, a defesa da família tradicional subalternizando outros arranjos, o incentivo ao armamento ${ }^{2}$, ataque a diferentes ideologias políticas, ataque às universidades públicas, a ciência e a liberdade de pensamento.

Destacamos os ataques as minorias e ao diferente, que não se enquadra no modelo normativo hegemônico, como mulheres, negros, índios, LGBTQIA+, que estão profundamente relacionados com a sustentação de um modelo econômico pautado na concentração de renda e na desigualdade, pois a subalternidade dos grupos sustenta os privilégios de uma parte da população, e não perceber a construção subjetiva da desigualdade mantém o arranjo atual. Então, longe de pensarmos a educação como a panaceia

\footnotetext{
${ }^{2}$ Parte da defesa dessas pautas podem ser observadas no discurso de pose da Presidência da República em 2019 e no seguimento de suas políticas e programas.
} 
dos problemas da sociedade, é necessário que pensemos o papel da escola, assumindo a possibilidade de enxergar e enfrentar a estrutura hierárquica desigual que constitui nossa sociedade e que isso nos transforme de modo a ver no outro diferença e não desigualdade. Perceber que a vida de privações do outro tem relação com sua vida de privilégios, pois não basta tolerar o outro como enfatiza o discurso da diversidade, é necessário transformar a si mesmo.

Historicamente, a escola é um espaço normativo, destinada aos homens brancos e livres. As lutas por direitos constituíram escolas diversas, com o reconhecimento do direito de mulheres, negros, índios, homossexuais. Entretanto, parte dessa incorporação do diverso implica não questionar privilégios estabelecidos, mantendo intocada uma "[...] cultura dominante criando apenas condições de tolerância para os diferentes, os estranhos, os outros" (MISKOLCl, 2012, p. 42). E o Brasil de hoje patina até mesmo nessa tolerância, legitimando discursos de ódio que incidem sobre a escola, a sala de aula, a subjetividade.

Entretanto, a escola também é feita de resistência, e a potência da subjetividade em volteio é capaz de realizar sob a perspectiva da diferença, no contexto da prática, políticas como a obrigatoriedade do ensino de História e Cultura Afro-Brasileira no ensino fundamental e médio e o Programa Brasil Sem Homofobia (2004), frutos da luta incansável de movimentos sociais. Ensinar e aprender sobre a história e a cultura afrobrasileira, sobre o combate a homofobia, a defesa dos direitos humanos e de outros seres, sob a perspectiva da diferença, pode produzir novos desejos e formas de cooperação com justiça social. Aqui reside a potência de vida, a potência queer das escolas que pode desfazer fronteiras.

Este ensaio teórico promove um diálogo entre as reflexões teóricas de Deleuze (1996), Miskolci (2012), Butler (2015) e Scott (2005), as pesquisas de Vianna (2015), Almeida e Sanches (2017), Barroso e Silva (2020), dados estatísticos do IBGE (2018, 2019), INEP (2015), Monitor da Violência (2018, 2019), o Programa Brasil Sem Homofobia (2004) e Lei 10.639/2003 que instituiu obrigatoriedade do ensino de História e Cultura Afro-Brasileira no ensino fundamental e médio. Apesar de constituir-se como instituição tradicional, as lutas dos diferentes estão presentes na escola, que se movimenta. O esforço aqui é de explicitar o território de lutas e diferenças na escola tramando os dados com a filosofia, produzindo territórios mentais, espaços de pensamento colaboradores em uma escola vitalizada.

\section{DIVERSIDADE OU DIFERENÇA? UNIVERSALISMO, IGUALDADE E ENFRETAMENTO}

A democracia é o espaço do conflito, do consenso e do dissenso, que ao mesmo tempo em que busca reconhecer o indivíduo universal, também precisa ser capaz de considerar suas diferenças, desafio constante. Direitos são históricos, alcançados em diversas conjunturas políticas, não são dados naturalmente e nem conquistados de uma única vez e nem de uma vez por todas (BOBBIO, 1988). O Estado de Direito, pautado nos princípios individuais do liberalismo, não foi dado naturalmente, e mesmo com todas as limitações, ainda que na democracia, foi construído com muitas lutas. Entretanto, lembremos que na Grécia Antiga, lócus da democracia, homens, brancos, livres e instruídos é que tinham o direito ao sufrágio.

$$
\text { Um marco importante no }
$$

reconhecimento dos indivíduos como sujeito de direito foi a Declaração Universal de Direitos Humanos (1948). Na década de 1990, como aponta Miskolci (2012), conflitos étnico-raciais e culturais, na Europa e na América do Norte, fomentaram 0 debate sobre as políticas apaziguadoras e conciliatórias para a diversidade. A publicação do artigo A Política do Reconhecimento, do filósofo canadense Charles Taylor $^{3}$, é uma referência para o seguimento do debate acadêmico e também para a elaboração de políticas públicas no âmbito da diversidade. Essa política de reconhecimento da diversidade, também denominada multiculturalismo, mantem as relações de poder intactas, "[...] serve a uma concepção horizontal de relações sociais que tem como objetivo evitar a divergência e, sobretudo, o conflito" (MISKOLCl, 2012, p. 44).

A Declaração de Nova Delhi - Educação para Todos (1993), Declaração de Princípios sobre a Tolerância (1995), Compromisso de Dakar Educação para Todos (2000), Declaração do Milênio das Nações Unidas (2000) e Declaração Universal sobre Diversidade Cultural (2002) foram elaboradas na esteira do debate sobre a diversidade étnica, racial, cultural e sexual. Tais

\footnotetext{
${ }^{3}$ É Professor Emérito de Filosofia e Ciência Política na Universidade de McGill no Canadá.
} 
declarações influenciaram a elaboração de políticas públicas para a educação na diversidade em diferentes países e pautaram-se no reconhecimento e tolerância à diversidade no processo educativo.

Para Butler (2015), as noções de tolerância e reconhecimento são problemáticas. A tolerância implica um desprezo por aqueles a quem é direcionada, pois a definição da diferenciação pressupõe uma norma. Quanto ao reconhecimento, quem o confere? Que forma este assume e o que precisa de reconhecimento (BUTLER, 2015) - a homossexualidade do gay, as religiões de matriz africana, a cultura das etnias indígenas?

O discurso da diversidade sob o multiculturalismo não questiona as classes sociais, é uma teoria do consenso que contorna os conflitos sociais, culturais e econômicos que constituem as sociedades desiguais. Propõe a tolerância e o reconhecimento a partir de uma perspectiva normativa que visa constituir uma convivência pacífica e uma igualdade abstrata sem questionar os privilégios dos homens, brancos, ricos, cristãos; não toca nas relações de poder que fundamentam a desigualdade e a subalternidade de grupos específicos. É "[...] uma vertente política construída sob a perspectiva daqueles que detêm o poder, já tem acesso a direitos e propõem estendê-los a outros sem modificar a estrutura institucional em que se baseiam" (MISKOLCl, 2012, p. 17).

Sob a perspectiva da diferença é fundamental problematizar a normatividade, o homem, branco, heterossexual e cisgênero que se utiliza de tais características para exercer poder sobre os outros. Quem define o que é normal e anormal? Porque o corpo, a aparência, os desejos e as crenças precisam de disciplinamento e controle para serem consideradas normais? Reconhecer os históricos conflitos econômicos, raciais, culturais, sexuais é condição básica para movimentar as instituições que perpetuam a desigualdade, como a família, a igreja, a propriedade privada e mesmo a escola.

Discutir a concepção das diferenças significa ouvir a voz daqueles que são continuamente silenciados pelas relações de poder hegemônicas. Para Miskolci (2012, p. 45), "[...] a perspectiva das diferenças nos convida sempre ao contato, ao diálogo, às divergências, mas também à negociação de consensos e à transformação da vida coletiva como um todo". A perspectiva das diferenças como enfrentamento e questionamento da ordem vigente coloca em xeque 0 enquadramento universalista dos direitos pensado para uma sociedade homogênea. Todos são iguais perante a lei?

A seguir apresentaremos alguns dados sobre o tratamento desigual destinado às minorias. Destacamos que minoria não representa apenas um definidor numérico dos grupos subjugados que não se enquadram na normatividade estabelecida, mas também a potência da transformação, um desestabilizador de uma maioria que não é necessariamente estatística, mas, sobretudo simbólica do poder instituído (DELEUZE, 1996).

No Brasil, a Constituição de 1824 garantia no artigo 179, inciso XXXII, "A Instrucção primaria, e gratuita a todos os Cidadãos" (BRASIL, 1824), porém poucos eram cidadãos. Problematizar o conceito de cidadania presente na Constituição sobre o direito à educação, implica pensar o colonialismo e a escravidão, a exclusão de mulheres, homens e mulheres negras e indígenas do estatuto de cidadão. A instrução primária, de acordo com a Lei de 15 de outubro de 1827, incluía ler, escrever, gramática de língua nacional, quatro operações de aritmética, prática de quebrados, decimais e proporções, noções mais gerais de geometria prática, princípios de moral cristã e da doutrina da religião católica e apostólica romana. Para as mulheres, foram excluídas as noções de geometria prática, prática de quebrados, decimais e proporções, princípios de moral cristã e da doutrina da religião católica e apostólica romana e acrescidas as "[...] prendas que servem à economia doméstica". É o arranjo que acirra a desigualdade, a igualdade é aquela que liberta, que transforma pela diferença, possível e necessária quando se quer mudança.

O universalismo baseado nos valores de que todos são iguais perante a lei foi assentado na subalternidade das mulheres, negros, indígenas e homossexuais. A mentalidade colonialista da supremacia branca dos homens e da heterossexualidade faz parte da formação da população brasileira, inclusive aquela realizada nas escolas, e todos os avanços em termos de direitos presentes na Constituição Cidadã de 1988 , conseguidos com muitas lutas sociais, ainda não abarcavam as desigualdades existentes no país fundadas em normas que distinguem cidadão de primeira, segunda, terceira classe. 
Sobre gênero e cor, a pesquisa ${ }^{4}$ realizada na Escola Nacional de Saúde Pública Sergio Arouca, Fundação Oswaldo Cruz, por Leal et al. (2017), mostrou que mulheres pretas sofrem maior violência obstétrica no Brasil. Em comparação com puérperas brancas, puérperas pretas possuíram maior risco de terem um prénatal inadequado, maior falta de vinculação à maternidade, maior ausência de acompanhante durante o pré-natal e menor uso de anestesia local para episiotomia (LEAL et al., 2017). Em pesquisa sobre o Rio de Janeiro, Leal et al. (2005), já evidenciava, entre os anos de 1991-2001, a menor utilização de procedimentos anestésicos no parto vaginal para mulheres pretas e pardas, sendo a proporção ainda menor para aquelas com menor escolaridade.

De acordo com Leal et al. (2017, p. 10), no caso do Rio de Janeiro, "[...] profissionais de saúde mencionaram uma suposta melhor adequação da pelve das mulheres pretas para parir, fato que justificaria a não utilização de analgesia". Pesquisa realizada por Hoffman et al. (2016) nos EUA, baseada em entrevistas com estudantes de medicina e residentes, identificou percepções sociais pautadas em supostas diferenças biológicas de acordo com a "raça", apontando pretos como mais resistentes a dor, o que configurou para os autores "racismo internalizado".

Quando se trata de remuneração e cor, dados do IBGE mostram que enquanto trabalhadores pretos e pardos recebem, em média, $R \$ 10,10$ por hora trabalhada no Brasil, os brancos recebem R\$ 17 por hora (IBGE, 2019). Entre os escolarizados a diferença diminui, mas persiste: negros, com pelo menos o ensino superior, ganham em média $\mathrm{R} \$ 22,70$ por hora de trabalho, e brancos R\$32,80 (IBGE, 2019).

Com relação à taxa de analfabetismo, de acordo com a Pesquisa Nacional por Amostra de Domicílio Contínua Educação (2019), 3,6\% das pessoas de 15 anos ou mais de cor branca eram analfabetas, entre pessoas de cor preta ou parda, a taxa é de $8,9 \%$. Para brasileiros com 60 anos ou mais, o percentual de analfabetismo foi de $9,5 \%$ entre pessoas brancas e pretos ou pardos a taxa chegou a $27,1 \%$.

Em agosto de 2006 foi sancionada a Lei 11.340, também conhecida como Lei Maria da

\footnotetext{
${ }^{4}$ Nascer no Brasil: Pesquisa Nacional sobre Parto e Nascimento: estudo de base populacional de abrangência nacional com entrevista e avaliação de prontuários de 23.894 mulheres em 2011/2012.
}

Penha, que cria mecanismos para coibir a violência doméstica e familiar contra a mulher. Em março de 2015 foi criada a Lei 13.104, também chamada de Lei do Feminicídio, que caracteriza o crime de ódio motivado pela condição de gênero, a mulher morre por ser mulher. De acordo com o Monitor da Violência (2018), entre 2003 e 2013, o número de homicídio passou de 3.937 para 4.762 mortes. As maiores vítimas do feminicídio são negras e jovens, com idade entre 18 e 30 anos. De acordo com os últimos dados do Mapa da Violência, a taxa de assassinato de mulheres negras aumentou 54\% em dez anos (WAISELFISZ, 2015). Em 2019, houve uma alta de $12 \%$ nos feminicídios no Brasil (MONITOR DA VIOLÊNCIA, 2019).

Dados do Núcleo de Estudos da Violência da USP e do Fórum Brasileiro de Segurança Pública mostram 3.777 mortes de mulheres em 2015, 4.021 em 2016 e 4.473 em 2017 (MONITOR DA VIOLÊNCIA, 2018). Do total de 4.021 vítimas em 2016, 946 morreram por serem mulheres. O Fórum Brasileiro de Segurança Pública apontou que houve um aumento de $22 \%$ nos registros de casos de feminicídio no Brasil durante a pandemia covid-19. A crise sanitária também agravou o quadro de violência e agressão contra meninas e mulheres.

De acordo com pesquisa da Fiocruz, utilizando dados do SUS, entre 2015 e 2017, foram 24.564 notificações de violências contra a população LGBT, significando mais de 22 notificações de violências interpessoais e autoprovocadas por dia (PINTO et al., 2020). A maior parte dos indivíduos alvos das agressões registradas (69\%) tinham idades entre 20 e 59 anos e metade era negra (50\%). Do total, $46,6 \%$ eram transexuais ou travestis e $57,6 \%$ eram homossexuais, dos quais $32,6 \%$ lésbicas e $25 \%$ gays (PINTO et al. 2020).

As estatísticas apresentadas nos ajudam a refletir sobre a constante tensão entre indivíduo e grupo. $O$ contrato liberal considera os indivíduos, mas diante de uma igualdade presumida na lei. No contexto da prática determinados grupos são discriminados e a legislação genérica é incapaz de atender os direitos desses indivíduos que são inferiorizados em sua diferença, pois, ao final, não somos todos diferentes? Quem diz quem é o diferente e quem é a norma? $O$ diferente é sempre o outro.

Scott (2005), ao discutir sobre a igualdade e a diferença, argumenta no sentido de pensar a 
igualdade em termos de paradoxo. Para ela a política é a negociação do impossível, e suas melhores soluções reconhecem o perigo de decisões totalizantes, seja em termos de igualdade ou diferença. Em sociedade democráticas, "[...] onde os problemas são mais intratáveis e menos passíveis de resolução é que a política mais importa" (SCOTT, 2005, p. 29).

Para Scott (2005) as identidades de grupo são inevitáveis na vida social e política e emergem de contexto políticos particulares. $\mathrm{Na}$ tensão permanente do dissenso e do consenso, a política pode promover uma igualdade que incorpore e se transforme pela diferença, e uma diferença que não produza e reproduza desigualdades. Gênero, raça, sexualidade, devem, para Miskolci (2012), ser pensados conjuntamente. Só assim é possível compreender a interseccionalidade das lutas sociais e constituir uma forma de vida não normatizada, e sim queer.

Queer é palavra de calão, em inglês: anormal, esquisito, estranho, veado. Em entendimento de assumir a diferença, passou a ser símbolo da resistência das pessoas marginalizadas, em especial no contexto da década de 1980 em função da vinculação da Síndrome da Imunodeficiência Adquirida (AIDS) com a homossexualidade. A Teoria Queer ${ }^{5}$ surge em contexto de questionamento de uma normatividade que exclui e subalterniza o que é considerado diferente. Miskolci (2012) chama a atenção para que a problemática queer não se refere estritamente a sexualidade, mas a abjeção, ao espaço que é relegado àqueles que rompem a ordem social, política e econômica em vigência, aqueles que ameaçam o privilégio do outro que é assentado em sua subalternidade. Para Miskolci (2002, p. 10), "Uma perspectiva queer exigiria repensar a educação a partir das experiências que foram historicamente subalternizadas, até mesmo ignoradas, mas que podem ajudar a repensar nossa sociedade, buscar superar injustiças e desigualdades".

\section{POLÍTICAS EDUCACIONAIS "PARA A DIVERSIDADE": A POTÊNCIA QUE ESCAPA AO TÍTULO}

\footnotetext{
5 "Teoria Queer surgiu apenas lá e teve como data de nascimento 1990, ano em que foram lançados três de seus livros mais influentes: Problemas de gênero, de Judith Butler, One Hundred Years of Homosexuality (Cem anos de homossexualidade), de David M. Halperin, e, sobretudo, o grande livro fundador da Teoria Queer, A epistemologia do armário, de Eve Kosofsky Sedgwick" (MISKOLCI, 2012, p. 23-24).
}

No Brasil, nos governos Lula (2003-2010), a discussão sobre a diversidade alcançou maior grau de institucionalização, todavia com concepções norteadoras associadas à perspectiva da diversidade (MOEHLECKE, 2009). É pertinente lembrar que em meados de 1980 estávamos saindo de uma ditatura militar que violou profundamente os direitos humanos ${ }^{6}$ e o processo de redemocratização significou a luta pelo reestabelecimento de direitos sociais e a constituição de novos. Em 2004, em parceria com organizações internacionais, foi criada no Brasil a SECAD, posteriormente chamada de SECADI ${ }^{7}$ (Secretaria de Educação Continuada, Alfabetização, Diversidade e Inclusão), responsável pela fomentação de políticas para a diversidade e a inclusão.

No Relatório de Gestão da SECAD de 2004 é possível vislumbrar uma agenda para a inclusão e a diversidade, bem como suas linhas de ação. Destaca-se a Educação de Jovens e Adultos, Educação do Campo, Educação Indígena, Educação para Diversidade Étnico-racial, Educação Quilombola, Apoio Educacional a Crianças e Adolescentes em Situação de Discriminação e Vulnerabilidade Social e Educação Ambiental (BRASIL, 2005). Em parceria com outras secretarias e órgãos foram elaboradas diferentes políticas para inclusão da diversidade e políticas afirmativas.

A partir de 2003 começaram as discussões para a elaboração do Plano Nacional da Educação em Direitos Humanos (PNEDH), finalizado e publicado em 2006. O Plano contemplou as muitas ações e políticas necessárias para o "[...] respeito à dignidade da pessoa humana, sem distinção de raça, nacionalidade, etnia, gênero, classe social, região, cultura, religião, orientação sexual, identidade de gênero, geração e deficiência" (BRASIL, 2007, p. 23). E mais do que o respeito à dignidade, o Plano apontou a necessidade de efetivar o direito à saúde, educação, moradia, ao lazer, ao meio ambiente saudável, ao saneamento básico, à segurança pública, ao trabalho e às diversidades culturais e religiosas.

O PNEDH abriu caminhos para elaborar políticas, em discussão com movimentos sociais e a sociedade civil, que objetivavam pensar a educação a partir do reconhecimento e inclusão

\footnotetext{
6 Ver relatórios da Comissão da Verdade: <http://cnv.memoriasreveladas.gov.br/>

${ }^{7}$ Extinta na gestão federal de Jair Bolsonaro pelo Decreto no 9.465, de 2 de janeiro de 2019
} 
de deficientes, negros, índios, LGBTQIA+ e mulheres em todos os espaços que historicamente lhe foram negados. Como exemplo, no campo das políticas educacionais, destacamos a Lei n. 10.639/03, que estabeleceu a obrigatoriedade da temática História e Cultura Afro-Brasileira nos estabelecimentos de ensino fundamental e médio, públicos e privados e o Programa Brasil Sem Homofobia - Programa de Combate à Violência e à Discriminação Contra GLBT e de Promoção da Cidadania Homossexual (BSH) de 2004, a fim de refletir sobre os impactos destas ações no contexto da prática das escolas.

A aprovação da Lei n. 10.639/03 representou uma vitória histórica do movimento negro. Expressou a garantia de um espaço no processo educativo de confronto a uma história única, a história dos brancos colonizadores. Como seria a história do Brasil se contada por mulheres? Mulheres negras? Diferentes etnias indígenas? Como nos lembra Adichie (2019), criamos uma história única contando, repetidas vezes, a história de um povo de modo definitivo diante de seu silêncio, e essa história única destrói sua dignidade, mas histórias, no plural, podem reparar essa dignidade arrancada de si. A história do Brasil possui muitas vozes que foram emudecidas nas relações de poder.

De acordo com Almeida e Sanchez (2017), a dificuldade na implementação da Lei $n$. $10.639 / 03$, refere-se aos problemas estruturais do sistema educacional brasileiro e suas bases ideológicas racistas. O sistema educacional constitui e reflete nossa sociedade, nossa história única. Em levantamento de produções acadêmicas, entre 2003 e 2010, as autoras apontam que o tema mais problematizado é a formação de professores, em específico o investimento em formação inicial e continuada em diálogo com a lei 10.639/03, refletindo a ausência de discussão sistemática do conteúdo da lei na realidade cotidiana e resistência de professores e gestores na aplicação da lei. Outra temática são os livros didáticos que reproduzem estereótipos e uma visão negativa sobre a população negra. Professores e livros podem reforçar uma história única, branca. Mas também podem contar e ouvir outras histórias.

Almeida e Sanchez (2017) apontam que a chegada de tais temáticas, história e cultura afrobrasileira, têm ocorrido de modo isolado no contexto das escolas, sem que haja uma discussão sistemática que problematize o Projeto Político Pedagógico (PPP) da escola. Há muita dificuldade em promover mudanças profundas, o que se deve, em partes, ao racismo institucionalizado que se expressa de forma difusa na distribuição de serviços, bens e oportunidades. A autonomia e protagonismo docentes, bem como atuação de movimentos sociais e financiamento de políticas e programas, são fundamentais para realizar a lei no contexto da prática, para promover mudanças na forma de viver e ser, e não apenas para introduzir temas de modo apaziguador ou mesmo burocratizante no contexto das escolas.

A introdução da história e da cultura afrobrasileira no currículo, sob a perspectiva da diversidade, é insuficiente para promover mudanças estruturais na escola e na sociedade. No contexto da prática, leis como a 10.639/03 podem ser realizadas sob a característica conciliatória do multiculturalismo, sem questionar as causas do silenciamento histórico da população negra, introduzindo dias de comemoração, em que negros e negras servem de modo caricato ao imaginário branco, vestindo, por exemplo, roupas que julgam ser "de negros". Datas como o Dia do Índio (19 de abril) e Dia da Consciência Negra (20 de novembro), podem ser mais do que celebrações, reflexões, memórias sobre como nossa forma de viver destruiu etnias inteiras e como esses resistiram ao silêncio imputado pela história do homem branco europeu heteronormativo. É fundamental entender que se tais datas fazem sentido é porque nos outros dias a desigualdade é hegemônica.

A história única também reconhece um tipo de relação afetiva, a heterossexual, essa é a norma, as outras são "anormais", que sofrem com a violência simbólica e física da homofobia, ou mesmo com a homofobia velada, pois não incomoda desde que permaneça no armário, então é tolerado. Na escola, ao assumir uma história única, temos o que Junqueira $(2012$, p. 493) denominou de Pedagogia do Armário, não apenas práticas informais de preconceitos, mas: "[...] dispositivos heteronormativos e práticas disciplinares se relacionam à edificação e à salvaguarda de valores e regimes de verdade heteronormativos, bem como de relações de poder heterocêntricas e de processos de (des)classificação, hierarquização e estruturação de privilégios heterossexistas, cujas arbitrariedades e iniquidades o currículo em ação, ao mesmo tempo que veicula, contribui para naturalizar e legitimar". 
Vianna (2015), ao analisar o Programa Brasil Sem Homofobia (BRASIL, 2004), pondera que o mesmo foi pautado pelo movimento LGBT, tendo o combate à homofobia, à violência física, verbal e simbólica, a defesa das identidades de gênero e da cidadania homossexual, como seus objetivos fundamentais. O programa também visava realizar a formação continuada de professores, promovendo discussões sobre gênero e sexualidade, sobretudo a capacidade de identificar e lidar com atos de violência física ou simbólica nos estabelecimentos educativos.

De acordo com Vianna (2015, p. 803), as políticas públicas e a prática das ações devem promover "[...] processo educativo para todos nós, em uma sociedade onde a segregação e as estratégias de esvaziamento das desigualdades são permanências históricas que devem ser superadas também no âmbito das relações sociais de gênero". A formação de professores é uma política sempre nas várias lutas pela garantia dos direitos humanos, como expresso nas ações vinculadas a Lei 10.639/03 e ao Programa Brasil Sem Homofobia.

Os desdobramentos do Programa trouxeram maior visibilidade à discussão sobre gênero e sexualidade, sobretudo com 0 protagonismo dos movimentos sociais, mas a falta de recursos financeiros para as ações foi um dos entraves para o desenvolvimento desde debate nas escolas (DANILIAUSKAS, 2011). "O debate sobre gênero e sexualidade, apesar de maior visibilidade, esbarra no conservadorismo da sociedade brasileira e na frágil perspectiva da diversidade, em que [...] as ações do Estado parecem querer valorizar a diversidade sexual sem considerar as relações de poder que a heteronormatividade chancela" (VIANNA, 2015, p. 802).

Vianna (2015) também destaca o veto da presidente Dilma Rousseff ao Kit Escola Sem Homofobia, material educativo elaborado para romper com a hierarquia e naturalização da heterossexualidade. Em maio de 2011, quando Dilma Rousseff vetou o material, o Supremo Tribunal Federal (STF) aprovou a união estável para pessoas do mesmo sexo. Lembremos também que os conceitos de gênero e orientação sexual foram suprimidos do Plano Nacional de Educação (PNE) 2014-2024 (AMARO, 2017) e da Base Nacional Comum Curricular (BNCC) 2017 (BARROSO; SILVA, 2020).

Vianna (2015, p. 801) aponta que "essa maior visibilidade não garantiu que tais questões fossem abordadas em sala de aula da maneira considerada adequada pelo governo". O desdobramento de políticas públicas que seriam fundamentais ao combate a homofobia, como o kit, as metas do PNE e o currículo, foram alvo de intensas disputas de poder no Congresso Nacional, espraiando-se em Câmaras Municipais pelo país, resultando na supremacia da posição conservadora das bancadas religiosas.

Treze anos após a aprovação da Lei 10.639/03, de acordo com dados do Censo Escolar de 2015, 24\% (12 mil) das escolas públicas do Brasil não abordam o racismo em seus projetos temáticos (INEP, 2015). Quanto a desigualdade social, $40 \%$ das escolas não abordam esse tema em suas atividades pedagógicas, e $52 \%$ não abordam a diversidade religiosa (INEP 2015). É interessante perceber as intersecções dos temas. Como combater o racismo sem diversidade religiosa? Como compreender o fenômeno pentecostal no Brasil sem abordar a desigualdade social?

De acordo com o IBGE (2018), entre 2016-2018, o acesso à educação básica obrigatória (4-17 anos) cresceu em todas as faixas etárias, todavia, quando é feito o recorte por cor, o crescimento do acesso é maior entre brancos $(55,8 \%)$ do que pretos e pardos $(40,3 \%)$. Também foi registrado o aumento da taxa de frequência líquida do Ensino Médio (15-17 anos), 69,3\%, entre brancos a frequência foi maior $(76,5 \%)$ do que pretos e pardos (64,9\%). A taxa de conclusão do Ensino Médio também aumentou de 46,2\% para $47,4 \%$, registrando percentual maior entre brancos $(55,8 \%)$ do que entre pretos e pardos $(40,3 \%)$ (IBGE, 2018).

O recorte étnico-racial deve ser levado em conta ao discutir a evasão escolar, assim como a homofobia. De acordo com a Pesquisa Nacional sobre o Ambiente Educacional no Brasil (2016), realizada pela Secretaria de Educação da Associação Brasileira de Lésbicas, Gays, Bissexuais, Travestis e Transexuais (ABGLT), 27\% dos estudantes LGBT de Educação Básica pesquisados, afirmaram ter sofrido agressão na escola e $73 \%$ foram agredidos verbalmente em função de sua orientação sexual. Desses estudantes, $68 \%$ foram xingados devido à identidade de gênero e $25 \%$ agredidos pelo mesmo motivo. Menos da metade desses estudantes, 42,4\%, informaram a escola alguma vez nos casos de agressão. E somente $18,7 \%$ indicaram que informaram sempre ou quase sempre os responsáveis da escola (ABGLT, 2016). 
Avanços políticos, em termos de legislação, programas e projetos, são essenciais para a garantia dos direitos humanos, o combate ao racismo e a homofobia. Mas é também necessária a transformação social, que pode acontecer, antes, simultaneamente ou mesmo a despeito de legislações. E, assim, narrativas políticas, diferentes vozes são também fundamentais na constituição de outras histórias e no enfretamento dos conflitos. Tímidos avanços nos governos de Lula foram insuficientes para o combate ao racismo e a homofobia, ficando a resistência das margens, dos movimentos sociais, como principal mecanismo de luta.

No Brasil de 2020, não temos tímidos avanços, temos retrocessos, não apenas conversadores, mas reacionários. O governo federal, além de extinguir a SECADI, possui uma narrativa política que incita o ódio, o racismo e a homofobia, de modo que a atuação não se insere nem mesmo sob a perspectiva da diversidade, com sua superficialidade apaziguadora e conciliatória da tolerância. $\mathrm{O}$ atual presidente da República profere regularmente falas racistas e homofóbicas, legitimando agressões verbais e físicas as populações historicamente penalizadas. No quadro a seguir podemos observar frases proferidas pelo atual presidente (FOLHA DE SÃO PAULO, 2020):

"O negão é o Hélio, hein. Meu irmão que demorou para nascer. Demorou 10 meses para nascer. O Hélio deu uma queimadinha. Deu uma queimadinha no Hélio aí. Senão, ele seria a minha cara" (fev.2020, durante live em rede social).

“Com toda a certeza, o índio mudou. Está evoluindo. Cada vez mais o índio é um ser humano igual a nós" (jan.2020, durante live em rede social).

"Quem quiser vir aqui [ao Brasil] fazer sexo com uma mulher, fique à vontade. O Brasil não pode ser um país de turismo gay. Temos famílias" (abr.2019, durante café da manhã com jornalistas).

"Fui num quilombola em Eldorado Paulista. Olha, o afrodescendente mais leve lá pesava 7 arrobas. Não fazem nada. Eu acho que nem para procriador ele serve mais" (abr.2017, quando ainda era deputado federal, durante palestra no Rio de Janeiro).

"Todos nós somos iguais perante a lei. Eu não entraria em um avião pilotado por um cotista, nem aceitaria ser operado por um médico cotista" (mar. 2011, entrevista ao programa CQC da TV Bandeirantes).

"Seria incapaz de amar um filho homossexual. Não vou dar uma de hipócrita aqui: prefiro que um filho meu morra num acidente do que apareça com um bigodudo por aí. Para mim ele vai ter morrido mesmo" (jun. 2011, Revista Playboy).

Quando temos líderes que legitimam racismo, homofobia e misoginia, a resistência se torna especialmente dramática. "O desespero da incerteza vira convicção inabalável" (DUNKER; THEBAS, 2019, p. 93). A história única sendo legitimada por lideranças políticas aumenta ainda mais a carga da educação enquanto possibilidade de desconstrução de discursos de ódio, vazios de ciência e humanidade. É dada uma missão hercúlea aos professores. O diálogo tão negado nesse Brasil distópico - Brasil que grita, mas não ouve - é a principal ferramenta da educação, como nos lembra Freire (2012, p. 51), ser dialógico "[...] não é dizer-se descomprometidamente dialógico; é vivenciar o diálogo. Ser dialógico é não invadir, é não manipular, é não 'sloganizar'. Ser dialógico é empenhar-se na transformação constante da realidade".
A política e a gestão realizadas no âmbito das instituições educacionais são expressões do diálogo e enigma da desigualdade, que envolve a micropolítica capaz de amalgamar igualdade e diferença sem descaracterizar a luta contra a sujeição capitalista e contra a violação dos direitos humanos mais básicos. Ainda que diante de um comando federal despreparado para a política democrática e seus desafios, a escola, mesmo com sua herança heteronormativa branca, tem possibilidades de resistência queer, colocando as subjetividades em volteios, possibilitando ir além da diversidade performática que apenas tolera. A escola não pode ser a panaceia dos problemas, mas pode ser um dos espaços de resistência em que as margens são incorporadas, em outras palavras, espaço comum de redes de diferenças. 


\section{O QUEER NAS ESCOLAS NO CONTEXTO DA PRÁTICA: SUBJETIVIDADE EM VOLTEIO}

Só se pode viver perto de outro, e conhecer outra pessoa, sem perigo de ódio, se a gente tem amor. Qualquer amor já é um pouquinho de saúde, um descanso na loucura (GUIMARÃES ROSA, 2018, p. 221).

Quando discutimos o contexto da prática, onde a política está sujeita a reinterpretação e recriação, estamos considerando efeitos e consequências inesperados, pois políticas não são simplesmente implementadas, são realizadas entre jogos de poder e disputa (BOWE; BALL; GOLD, 1992). Concordamos com Pélbart (2002, p. 35-36), que mesmo a exploração não é imposta “[...] unilateralmente de cima para baixo, já que essa subjetividade vampirizada, essas redes de sentido expropriadas, esses territórios de existência comercializados, essas formas de vida visadas não constituem uma massa inerte $e$ passiva à mercê do capital, mas um conjunto vivo de estratégias".

Como a escola, composta por professores, estudantes, servidores, pais e a comunidade, vive e atua no cenário de desigualdades e também diante da Lei 10.639/03 e do Programa Brasil Sem Homofobia? Como legislações são recebidas e realizadas no contexto da prática? A legislação é apenas uma parte da política, o seu acontecimento na prática é uma parte fundamental e seu uso de maneira queer, não normativa, pode modificar o processo educacional, em contraponto às práticas normativas contra os diferentes, que são sempre os outros. Como destaca Miskolci (2012, p. 14), "uma perspectiva não normativa pode causar mudanças mesmo dentro de programas que têm o título de diversidade".

Lembremos que o queer "[...] não é uma defesa da homossexualidade, é a recusa dos valores morais violentos que instituem e fazem valer a linha da abjeção, essa fronteira rígida entre os que são socialmente aceitos e os que são relegados à humilhação e ao desprezo coletivo" (MISKOLCl, 2012, p. 19). O queer se refere ao insubordinado, à fuga dos binarismos que subalternizam uma parte da população (branco, negro; homem, mulher; normal, anormal; heterossexual, homossexual; indivíduo, sociedade; natureza, cultura). Não se trata de identificar um outro, e sim do diálogo entre um e outro, considerando que a potência está no " $\mathrm{e}$ ", no encontro. No contexto da prática da escola, "Ao invés de punir, vigiar ou controlar aqueles e aquelas que rompem as normas que buscam enquadrá-los, o educador e a educadora podem se inspirar nessas expressões de dissidência para o próprio educar" (MISKOLCl, 2012, p. 58).

A educação é produtora de subjetividade, e pode fazer circular o poder, constituindo potência de vida. "Através dos fluxos da imagem, de informação, de conhecimento e de serviços que acessamos constantemente, absorvemos maneiras de viver, sentidos de vida, consumimos toneladas de subjetividade" (PÉLBART, 2002, p. 34). Uma subjetividade potente é o contrário de submissão, pois propõe pensar o poder como campo social de forças e não como ação de apenas uma pequena parte da população que ocupa cargos políticos. O poder se realiza de vários lados, não é um objeto que se encontra em lugar privilegiado que se pode ocupar e assaltar. A luta é pela realização dos direitos humanos e de outras vidas sem perder de vista a afirmação de uma miríade de diferenças. Igualdade não se opõe a diferença, mas a propicia (LAZZARATO, 2006).

Uma escola queer pode contribuir com a criação de laços de diferentes naturezas e a produção de territórios existenciais e subjetivos na contramão da heteronormatividade branca e colonialista que sustenta o capitalismo e sua exploração. A potência está nas margens, nos excluídos, nos silenciados, nos subalternizados, estes têm muito a ensinar para constituir a escola queer, pois "a invenção não é prerrogativa dos grandes gênios, nem monopólio da indústria e da ciência, ela é a potência do homem comum" (PÉLBART, 2002, p. 38).

No Brasil, mesmo diante do cenário social e educacional caótico, que exacerba e expõe a desigualdade sob a justificativa do mérito, a área de Política Educacional não deve se limitar a denunciar os problemas, mas construir outros mundos possíveis, e isso começa pelo microcosmo que é a sala de aula, ali ensaiamos o que queremos para o mundo, a transformação na diferença, o questionamento dos privilégios que aprofundam a desigualdade. Esta é uma política potente, que luta e sonha.

\section{REFERÊNCIAS}


ABGLT. Pesquisa Nacional sobre o Ambiente Educacional no Brasil (2016): as experiências de adolescentes e jovens lésbicas, gays, bissexuais, travestis e transexuais em nossos ambientes educacionais. Curitiba: ABGLT, 2016.

ADICHIE, C. N. O perigo de uma história única. 1a ed. São Paulo: Companhia das Letras, 2019.

ALMEIDA, M. A. B; SANCHEZ, L. P. Implementação da Lei 10.639/2003 - competências, habilidades e pesquisas para a transformação social. Proposições, Campinas, v. 28, n. 1, p. 55-80, jan./abr. 2017. https://doi.org/10.1590/1980-6248-2015$\underline{0141}$

AMARO, I. A docência no armário: o silenciamento das relações de gênero nos planos de educação. Espaço Pedagógico, Passo Fundo, v. 24, n. 1, p. 139-159, jan./abr. 2017.

BARROSO, R. R. J; SILVA, L. C. M. Gênero e Sexualidade na Educação brasileira em tempos de Movimento Escola Sem Partido. Revista Diversidade e Educação, Rio Grande, v. 8 , n. 1 , p. 427-451, Jan./Jun. 2020.

BALL, S. J. Educação global S.A.: novas redes políticas e o imaginário neoliberal. Ponta Grossa: Editora UEPG, 2012.

BRASIL. Conselho Nacional de Combate à Discriminação. Brasil Sem Homofobia - Programa de Combate à Violência e à Discriminação Contra GLBT e de Promoção da Cidadania Homossexual. Brasília: Ministério da Saúde, 2004.

BRASIL. Resolução CNE/CEB no 8, de 20 de novembro de 2012. Define Diretrizes Curriculares Nacionais para a Educação Escolar Quilombola na Educação Básica. Brasília: MEC, 2012.

BRASIL. Instituto Nacional de Estudos e Pesquisas Educacionais Anísio Teixeira. Censo da Educação Básica: Sinopse Estatística da Educação Básica 2015. Disponível em: http://www.inep.gov.br/superior/censosuperior/ sinopse. Acesso em: 16 abr. 2020.

BRASIL. Ministério da Educação. Resolução CNE/CP no 1, de 17 de junho de 2004. Diretrizes Curriculares Nacionais para a Educação das Relações Étnico-Raciais e para o ensino de História da Cultura Afro-Brasileira e Africana.
Brasília, MEC/Secretaria Especial de Políticas de Promoção da Igualdade Racial, 2004.

BRASIL. Lei n.13.005, de 25 de junho de 2014. Aprova o Plano Nacional de Educação - PNE e dá outras providências. Diário Oficial da União, Brasília, DF., 26 jun. 2014.

BRASIL. Plano Nacional de Educação em Direitos Humanos. Comitê Nacional de Educação em Direitos Humanos. Brasília: Secretaria Especial dos Direitos Humanos, Ministério da Educação, Ministério da Justiça, UNESCO, 2007.

BRASIL. Relatório de Gestão da SECAD - 2004. Brasília: SECAD, 20051)

BRASIL. Resolução CNE/CEB no 1, de 3 de abril de 2002. Institui diretrizes operacionais para a educação básica nas escolas do campo.

BRASIL. Resolução no 5, de 22 de junho de 2012. Define Diretrizes Curriculares Nacionais para a Educação Escolar Indígena na Educação Básica.

BOBBIO, N. Era dos direitos. Rio de Janeiro: Campus, 1988.

BOWE, R.; BALL, S.; GOLD, A. Reforming education \& changing schools: case studies in policy sociology. London: Routledge, 1992.

BUTLER, J. Quadros de Guerra: quando a vida é passível de luto. Rio de Janeiro: Civilização Brasileira, 2015.

DANILIAUSKAS, M. Relações de gênero, diversidade sexual e políticas públicas de educação: uma análise do Programa Brasil Sem Homofobia. 2011. 161f. Dissertação (Mestrado em Educação). São Paulo: Universidade de São Paulo, 2011.

DELEUZE, G. Abecedário. 1996. Disponível em: http://www.oestrangeiro.net/index.php?option= com content\&task=view\&id=67\&/temid=51.

Acesso: 15 out. 2020.

DELEUZE, G; FOUCAULT, M. Os intelectuais e o poder. In: DELEUZE, G. A ilha deserta e outros textos. São Paulo: Editora lluminuras, 2005.

DUNKER, Christian; THEBAS, Cláudio. 0 palhaço e o psicanalista: como escutar os outros pode 
transformar vidas. São Paulo: Planeta do Brasil, 2019.

FOLHA DE SÃO PAULO. Veja falas preconceituosas de Bolsonaro e o que diz a lei sobre injúria e racismo. 26 jan. 2020. Disponível em:

https://www1.folha.uol.com.br/poder/2020/01/v eja-falas-preconceituosas-de-bolsonaro-e-o-quediz-a-lei-sobre-injuria-e-racismo.shtml. Acesso em: 27 jan. 2020.

FREIRE, Paulo. Extensão ou comunicação? Rio de Janeiro: Paz e Terra, 2015.

HOFFMAN KM, TRAWALTER S, AXT JR, OLIVER $M N$. Racial bias in pain assessment and treatment recommendations, and false beliefs about biological differences between blacks and whites. Proc Natl Acad Sci, USA, n. 113, p. 4296-4301, $2016 . \quad$ Disponível em: https://doi.org/10.1073/pnas.1516047113.

Acesso em: 17 out. 2020.

IBGE. Pesquisa Nacional por Amostra de Domicílios (PNAD). 2018. Disponível em: www.ibge.gov.br. Acesso em: 14 out. 2020.

IBGE. Pretos ou pardos estão mais escolarizados, mas desigualdade em relação aos brancos permanece. Pesquisa Nacional por Amostra de Domicílios (PNAD) 2019. Disponível em: https://agenciadenoticias.ibge.gov.br. Acesso em: 14 out. 2020.

INEP. Instituto Nacional de Estudos e Pesquisas Educacionais Anísio Teixeira. Resumo Técnico: Censo da Educação Básica 2015. Brasília: Instituto Nacional de Estudos e Pesquisas Educacionais Anísio Teixeira, 2015.

JUNQUEIRA, R. D. Pedagogia do armário: A normatividade em ação Revista Retratos da Escola, Brasília, v. 7, n. 13, p. 481-498, jul./dez. 2013.

LAZZARATO, Maurizio. As Revoluções do Capitalismo. Rio de Janeiro: Record, 2006.

LEAL MC, GAMA SGN, CUNHA CB. Racial, sociodemographic, and prenatal and childbirth care inequalities in Brazil, 1999-2001. Rev. Saúde Pública, n. 39, p. 100-107, 2005,
https://doi.org/10.1590/S0034$\underline{89102005000100013}$

MISKOLCl, R. Teoria Queer: um aprendizado pelas diferenças. Belo Horizonte: Autêntica Editora/UFPO, 2012.

MOEHLECKE, S. As políticas de diversidade na educação no governo Lula. Cadernos de Pesquisa, São Paulo, v. 39, n. 137, p.461-487, maio/ago. 2009. Disponível em: https://doi.org/10.1590/S0100-

15742009000200008. Acesso em: 14 out. 2020.

MONITOR DA VIOLÊNCIA. Cresce o no de mulheres vítimas de homicídio no Brasil: dados de feminicídio são subnotificados. 2018. Disponível em: https://g1.globo.com/monitor-daviolencia/noticia/cresce-n-de-mulheres-vitimasde-homicidio-no-brasil-dados-de-feminicidio-saosubnotificados.ghtml Acesso em: 14 out. 2020.

MONITOR DA VIOLÊNCIA. Mesmo com queda recorde de mortes de mulheres, Brasil tem alta no número de feminicídios em 2019. 2019. Disponível em: https://g1.globo.com/monitor-daviolencia/noticia/2020/03/05/mesmo-comqueda-recorde-de-mortes-de-mulheres-brasiltem-alta-no-numero-de-feminicidios-em2019.ghtml Acesso em: 14 out. 2020.

ONU. Declaração Universal de Direitos Humanos. $1948 . \quad$ Disponível em: http://www.onu.org.br/img/2014/09/DUDH.pdf. Acesso em: 14 out. 2020.

PELBART, P. P. O poder sobre a vida, potência de vida. Lugar Comum, n. 17, p. 33-43, 2002.

PINTO, Isabella Vitral et al. Perfil das notificações de violências em lésbicas, gays, bissexuais, travestis e transexuais registradas no Sistema de Informação de Agravos de Notificação, Brasil, 2015 a 2017. Rev. bras. epidemiol., Rio de Janeiro , v. 23, supl. 1, e200006.SUPL.1, 2020. https://doi.org/10.1590/1980-

549720200006.supl.1

ROSA, Guimarães. Grande Sertão: Veredas. 22a ed. São Paulo: Cia das Letras, 2019.

SCOTT, J. O enigma da igualdade. Estudos Feministas, Florianópolis, v. 13, n. 1, p. 11-30, 
jan./abr. 2005. https://doi.org/10.1590/S0104$\underline{026 \times 2005000100002}$

UNESCO. Declaração de Princípios sobre a

Tolerância. 1995. Disponível em:

http://unesdoc.unesco.org/images/0013/001315

1131524porb.pdf Acesso em 7 maio 2018.

UNESCO. Compromisso de Dakar. 2000.

Disponível em:

http://unesdoc.unesco.org/images/0012/001275

L127509porb.pdf. Acesso em 7 maio 2018.

UNESCO. Declaração de Nova Delhi. 1993.

Disponível em:

http://unesdoc.unesco.org/images/0013/001393

139393por.pdf. Acesso em 7 maio 2018.

UNESCO. Declaração do Milênio. 2000.

Disponível em:

https://www.unric.org/html/portuguese/uninfo/

DecdoMil.pdf. Acesso em 7 maio 2018.

UNESCO. Declaração Universal sobre

Diversidade Cultural. 2002. Disponível em: http://unesdoc.unesco.org/images/0012/001271 L127160por.pdf. Acesso em 7 maio 2018.

VIANNA, C. P. O movimento LGBT e as políticas de educação de gênero e diversidade sexual: perdas, ganhos e desafios. Educação e Pesquisa, São Paulo, v. 41, n. 3, p. 791-806, jul./set., 2015. https://doi.org/10.1590/s1517-97022015031914

WAISELFISZ, J. J. Mapa da Violência 2015: Homicídio de mulheres no Brasil. Brasília: OPAS/OMS, ONU Mulheres, SPM e Flacso, 2015. 